\title{
Bacteriological Profile of Bacteria isolated from Skin and Soft Tissue Infections
}

\section{Fatma A. Ahmed ${ }^{(1)}$, Rasha H. Bassyouni ${ }^{(2)}$, Yasmin Mahmoud Zedan ${ }^{(3)}$.}

(1)Lecturer of Medical Microbiology and Immunology, Factulty of Medicine Fayoum Univeristy.

(2)Professor of Medical Microbiology and Immunology, Factulty of Medicine Fayoum Univeristy.

(3) Department of Medical Microbiology and Immunology, Factulty of Medicine Fayoum Univeristy.

Corresponding author: Fatma A. Ahmed

E-mail adress: fan11@ fayoum.edu.eg

Tel: 01004285966

\begin{abstract}
Background: Skin \& soft tissue infections (SSTIs ) are common type of infections either community or hospital aquired with a significant morbidity.
\end{abstract}

Aims: To identify the microbiological profile of Gram negative bacteria causing skin and soft tissue infections with detection of antibiotic susceptibility pattern of isolates.

Material and methods: A crosssectional study of skin and soft tissue infections was conducted from April 2019 till January 2020. A total of 200 pus samples from SSTIs obtained from patients at the general surgery outpatient clinic of Fayoum University Hospital. Bacterial isolation and identification was performed according to conventional microbiological methods. Antimicrobial susebtipilty test was performed by Kirby-Bauer Disc diffusion method.

Results: A total of 197 bacteria were isolated from 200 pus samples. There were 129/197 (65.4\%) Gram positive cocci and 68 (34.5\%) Gram negative bacilli. Among the Gram negative bacilli, Pseudomonas aeruginosa was the most common isolated organism (28/197 (14.2\%) followed by Klebsiella species (27/197 (13.7\%). About 
11/68 (16.2\%) of the Gram - negative bacteria isolates was identefied as Extended spectrum beta lactamase (ESBL) while 23/68 (33.8\%) were carbapenem resistant. Gram - negative bacteria were most susceptible to piperacillin/ Tazobactam and meropinam (45 /68 (66.2\%) and 44/68 (64.4\%) respectively).

Conclusion: An alarming increase in antibiotic resistant pattern of Gram negative bacilli causing SSTIs was reported. Wise use of antibiotics and implementation of antimicrobial steweredship is a mandatory need nowaday.

Key Words - Skin \& soft tissue infections , Extended spectrum beta lactamase, Antibiotic susceptibility pattern.

\section{1) Introduction}

Skin and soft tissue infections (SSTIs) are characterized by inflammatory microbial invasions of the epidermis, dermis and subcautenous tissue, which can result in prolonged hospitalization, disability, and antibiotic therapy allover the world [1]. Several factors can contributes in SSTI classification, such as site of infection, causative agent, , depth of infection, clinical presentation, prognosis and severity of infection [2]. The most common organisms that are involved in community acquired SSTIs include gram-positive cocci-like Staphylococcus aureus, Staphylococcus pyogenes infection [2]. Recently Gramnegative bacteria, such as Escherichia coli and pseudomonas aurginosa started to be an emerging pathogen that affect morbidity and mortality in skin and soft tissues [3]. Gram-negative bacteria as $P$. aeruginosa and Klebsiella species are resistant to some (multidrug resistant) or all (Pandrug resistant) of the antibiotic classes commonly used to treat Gram-negative bacteria: penicillins, cephalosporins, carbapenems, monobactams, quinolons, aminoglycosides, tetracyclins and polymyxins [3]. Efficient treatment of these infection depend on recgnition of microbiological charactristics and antimicrobial resistance [4]. Since limited data are available concerning soft tissue infection, mortality rate and antibiotic susceptibility of Gram-negative bacteria in our hospital settings, this study aimed to evaluate the clinical and bacteriological profiles of bacterial isolates in skin and soft tissue infection including, the number and 
type of potential bacteriological pathogens along with antibiotic susceptibility and pattern of isolates.

\section{2) Material and Methods}

A cross-sectional study of skin and soft tissue infection was conducted from April 2019 till January 2020, clinical samples were obtained from the patients at general surgery outpatient clinic of Fayoum University Hospital, the collected samples were processed at the Department of Medical Microbiology and Immunology, Faculty of Medicine, Fayoum University. The study was approved by Fayoum Faculty of Medicine Ethical Committee (no.58)

\section{1) Collection of samples}

The lesions were cleaned with sterile normal saline. Special care was taken to avoid contamination by normal flora of skin or mucus surface, where possible pus was aspirated or exudates collected, and serial number were given to code each specimen with careful labeling. The specimens were transported within 2 hours to the laboratory.

\section{2) Bacterial identification}

Specimens were inoculated onto different culture media including (nutrient agar, MacConkey agar, blood agar) (Oxoid Ltd., Basingstoke, UK) under aerobic and anaerobic conditions (using candle jar method) at $37{ }^{\circ} \mathrm{C}$ overnight. The isolates were identified by Gram staining, colony morphology and standard biochemical tests: catalase, slide and tube coagulase, oxidase, esculin hydrolysis, bacitracin sensitivity test, indole production, citrate utilization, $\mathrm{H} 2 \mathrm{~S}$ production, urease, and triple sugar iron fermentation tests [5].

\section{3 ) Antimicrobial susceptibility testing}

Antibiotic susceptibility tests were performed using Kirby-Bauer Disc diffusion method on Mueller-Hinton agar (MHA) (bioMérieux, Marcy L'Etoile, France) according to Clinical and Laboratory Standard Institute (CLSI) guidelines. The following antibiotics were tested (Oxoid Ltd., Basingstoke, UK): Amoxicillin (25 $\mu \mathrm{g})$, Amoxicillin / Clavulanic acid $(20 / 10 \mu \mathrm{g})$, oxacillin $(1 \mu \mathrm{g})$, piperacillin-tazobactam

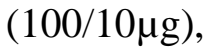
erythromycin $(15 \mu \mathrm{g})$, azithromycin $(15 \mu \mathrm{g})$ ceftriaxone $(30 \mu \mathrm{g})$, Cefepime $(30 \mu \mathrm{g})$, cefoxitin $(30 \mu \mathrm{g})$, Meropinam $(10 \mu \mathrm{g})$ [6]. 


\section{4) Extended spectrum beta lactamase and carbapenem resistant detection}

Double- disc synergy test: The test inoculum (0.5 McFarland turbidity) was spread onto Mueller-Hinton agar (MHA) (bioMérieux, Marcy L’Etoile, France) using a sterile cotton swab. A disc of ((Oxoid Ltd., Basingstoke, UK) Amoxicillin / Clavulanic acid (AMC) $(20 / 10 \mu \mathrm{g})$ was placed on the surface of MHA; then discs of cefpodoxime
(30 $\mu \mathrm{g})$, ceftriaxone $(30 \mu \mathrm{g})$, Cefepime $(30 \mu \mathrm{g}), \quad$ cefoxitin $(30 \mu \mathrm{g})$, Meropinam (10 $\mu \mathrm{g})$ were kept around it in such a way that each disc was at distance ranging between 16 and $20 \mathrm{~mm}$ from (AMC) disc (centre to centre). The plate was incubated at $37{ }^{\circ} \mathrm{C}$ overnight.The organisms were considered to be producing ESBL when the zone of inhibition around any of the expandedspectrum cephalosporin discs showed a clear-cut increase towards the augmentin disc. Meropinam resistance was used as the indication for carbapenemase production [7].

\section{3) Results}

Of the 200 samples 197 culture showed bacterial growth. All positive samples carried single pathogen. Higher distribution of infection was demonstrated among male patients (57.9\%). Range of age was (1.5y to $70 y$ ) with mean value of age was 35.5 . Data are expressed in the form of mean \pm standard deviation (SD) (Table.1).

Table 1: Demographic characteristics of patients included in the study

\begin{tabular}{|l|c|c|}
\hline \multirow{2}{*}{ Ages (years) } & Mean & SD \\
\cline { 2 - 3 } & 35.5 & 17.9 \\
\hline Sex (N=197) & $\mathrm{N}$ & $\%$ \\
\hline Male & 114 & $57.9 \%$ \\
\hline Female & 83 & $42.1 \%$ \\
\hline
\end{tabular}


By studying Skin and soft tissue infections distribution among different body site, extremities were the most affected site $(150 / 197,76.1 \%)$ while head and neck were the least affected site $(3 / 197,1.5 \%)$. The most prevalent type of infection was abscess formation which represented $175 / 197$ (88.8\%) out of the total cases (Table. 2).

Table 2: Sites and types of skin and soft tissue infections

\begin{tabular}{|l|c|c|}
\hline Site of infection & (N) & (\%) \\
\hline Extremities & 150 & $76.1 \%$ \\
\hline Trunk & 44 & $22.3 \%$ \\
\hline Head and Neck & 3 & $1.6 \%$ \\
\hline Type of infection & 175 & $88.8 \%$ \\
\hline Abscesses & 22 & $11.2 \%$ \\
\hline Surgical Site Infections & & \\
\hline
\end{tabular}

Out of the 197 isolates 129 (65.4\%) were Gram positive cocci and 68 (34.5\%) were Gram negative bacilli.

Pseudomonas aeruginosa had the highest prevalence 28/197 (14.2\%), while Proteus species was the least frequent isolated bacteria 5/197 (2.5\%) (Table. 3).

Table 3: Type of isolated bacteria

\begin{tabular}{|l|c|c|}
\hline Type of isolated bacteria & (N) (Total=197) & (\%) \\
\hline E- coli & 8 & $4.06 \%$ \\
\hline Klebsiella species & 27 & $13.7 \%$ \\
\hline Proteus species & 5 & $2.5 \%$ \\
\hline Pseudomonas aeruginosa & 28 & $14.2 \%$ \\
\hline Staphylococcus aureus & 129 & $65.4 \%$ \\
\hline
\end{tabular}


Antibiotic susceptibility pattern of isolated Gram-negative bacteria is given in (Table. 4).

Table 4: Antimicrobial susceptibility among Gram-negative bacteria

\begin{tabular}{|c|c|c|c|c|c|c|}
\hline \multirow[t]{3}{*}{ Antibiotic } & \multicolumn{6}{|c|}{ Gram- negative bacteria } \\
\hline & \multicolumn{2}{|c|}{ Sensitive } & \multicolumn{2}{|c|}{ Intermediate } & \multicolumn{2}{|c|}{ Resistant } \\
\hline & $\mathbf{N}$ & $\%$ & $\mathbf{N}$ & $\%$ & $\mathbf{N}$ & $\%$ \\
\hline Erythromycin & 22 & $32.4 \%$ & 0 & $0.0 \%$ & 46 & $67.6 \%$ \\
\hline Azithromycin & 21 & $30.9 \%$ & 8 & $11.8 \%$ & 39 & $57.4 \%$ \\
\hline Amoxicillin, Clavulanic acid & 29 & $42.6 \%$ & 0 & $0.0 \%$ & 39 & $57.4 \%$ \\
\hline Cefoxitin & 35 & $51.5 \%$ & 0 & $0.0 \%$ & 33 & $48.5 \%$ \\
\hline piperacillin/tazobactam & 45 & $66.2 \%$ & 0 & $0.0 \%$ & 23 & $33.8 \%$ \\
\hline Ceftriaxone & 25 & $36.8 \%$ & 0 & $0.0 \%$ & 43 & $63.2 \%$ \\
\hline Meropinam & 44 & $64.7 \%$ & 0 & $0.0 \%$ & 24 & $35.3 \%$ \\
\hline Cefepime & 22 & $32.4 \%$ & 0 & $0.0 \%$ & 46 & $67.6 \%$ \\
\hline
\end{tabular}

Our results showed that, 23/68 isolates of Gram-negative bacteria (32.2\%) were carbapenem resistant and 11/68 isolates (15.4\%) were extended spectrum beta lactamase (ESBL) producing isolates. Klebsiella spp isolates were the most resistant isolates, among Klebsiella spp. 13 /27 (48.1\%) were carbapenem resistant and 7/27 (25.9\%) were ESBL (Resistance to penicillin, cephalosporins and monobactam aztreonam) (Table. 5), (Figure. 1). 
Table 5: Frequency of Extended spectrum beta lactamase producers and carbapenem resistant among Gram - negative isolates

\begin{tabular}{|c|c|c|c|c|c|c|c|c|}
\hline \multirow{3}{*}{ Type of resistance } & \multicolumn{8}{|c|}{$\begin{array}{l}\text { Gram - negative bacteria } \\
\qquad(\mathrm{N}=68)\end{array}$} \\
\hline & \multicolumn{2}{|c|}{$\begin{array}{l}\text { E coli } \\
(\mathrm{N}=8)\end{array}$} & \multicolumn{2}{|c|}{$\begin{array}{l}\text { Klebsiella spp } \\
\qquad(\mathrm{N}=27)\end{array}$} & \multicolumn{2}{|c|}{$\begin{array}{c}\text { Pseudomonas } \\
\text { aeruginosa } \\
(\mathrm{N}=\mathbf{2 8})\end{array}$} & \multicolumn{2}{|c|}{$\begin{array}{c}\text { Proteus spp } \\
(\mathrm{N}=5)\end{array}$} \\
\hline & $\mathbf{N}$ & $\%$ & $\mathbf{N}$ & $\%$ & $\mathbf{N}$ & $\%$ & $\mathbf{N}$ & $\%$ \\
\hline $\begin{array}{r}\text { Carbapenem resistant } \\
\qquad(\mathrm{N}=\mathbf{2 3})\end{array}$ & 0 & $0.0 \%$ & 13 & $48.1 \%$ & 10 & $35.7 \%$ & 0 & $0 \%$ \\
\hline $\begin{array}{l}\text { Extended } \\
\text { lactamase producers } \\
\\
(\mathrm{N}=11)\end{array}$ & 0 & $0.0 \%$ & 7 & $25.9 \%$ & 4 & $14.3 \%$ & 0 & $0 \%$ \\
\hline
\end{tabular}




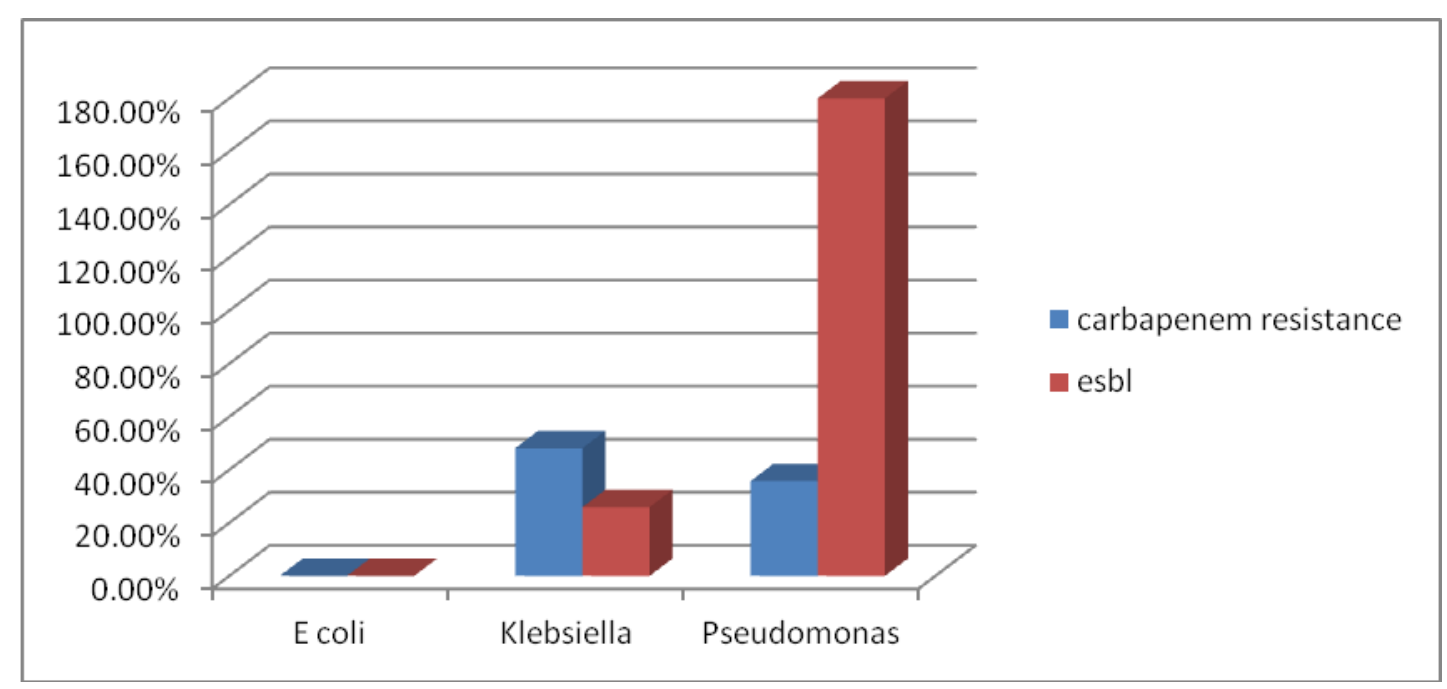

Figure. 1: Percentage of Extended spectrum beta lactamase producers and carbapenem resistant among Gram -negative bacteria

\section{(4)Discussion}

Antimicrobial resistant Gram-negative bacteria are one of the most important current threats to public health. The spread of resistant bacteria into the community is a crucial development, and is associated with increased morbidity, mortality, healthcare costs and antibiotic use. Prompt identification of the causative pathogen requires that patients with SSTI be risk stratified according to the likelihood of resistance to enable early recognition and swift initiation of appropriate therapy. Our study aimed to assess the expanding role of Gram-negative bacteria in skin and soft tissue infections and their antibiotic susceptibility pattern. Higher distribution of infection was 
demonstrated among male patients (57.9\%) with mean value of age 35.5 which come in agreement with Malhotra et al, (2012) where the percentage of male was (67.21\%) and the major age group was $31-40$ years [8]. Pseudomonas aeruginosa was the most predominant organisms among the Gram-negative bacteria, similar finding was reported in a study conducted by Mohanty et al, (2004), Pseudomonas aeruginosa was the most frequently isolated organism among the predominant five organisms isolated from skin and soft tissue infections in patient admitted to the hospital [9]. Maximum resistance of Gram-negative bacteria was seen against azithromycin 47(69\%), erythromycin $46(67.6 \%)$ and cephalosporins like cefepime 46 $(67.6 \%)$ and ceftriaxone 43(63.2\%) followed by amoxicillin, clavulanic acid 39 (57\%) which come in partial agreement with Afroz et al, (2015) where the percentage of cephalosporins resistant GNB were (90.32\%) [10]. Resistance of Gram-negative organisms was minimum against piperacillin/tazobactam 23(33.8\%)

followed by meropenem 24 (35.4\%) and Cefoxitin (57.4\%) which is like other studies 11,12 13. Our results showed that, 23/68 isolates of gramnegative bacteria $(32.2 \%)$ were carbapenem resistant and 11/68 isolates (15.4\%) were ESBL producing isolates. Klebsiella spp was the most resistant isolated Gram-negative bacteria, 13/27 (48.1\%) were carbapenem resistant and 7/23(30.4\%) were ESBL producers. This rate of resistance is lower than other studies conducted in India on soft tissue infections which documented $72.37 \%$ ESBL producers among E. coli, 68.79\% among Acinetobacter spp and 58.9\% among Pseudomonas spp [9]. Use of antibiotics, inappropriate dose and duration of antibiotics, lack of compliance to the hospital antibiotic policy, lack of awareness among the prescribing clinicians and patients about antibiotic resistance are the main underlying factors of exaggeration of antimicrobial resistance [14].

\section{5) Conclusion}


In this present study the most common isolate in skin and soft tissue infection among Gram-negative bacteria is Pseudomonas aeruginosa followed by Klebsiella spp. The alarming rise in multi drug resistant Gram-negative bacteria infections implement the great need to identifying the epidemiology of the bacteria causing skin and soft tissue infections and their sensitivity pattern. Following antibiotic stewardship will help in avoiding unnecessary medication with ineffective antibiotics and prevent development drug resistance.

\section{6) References}

[1]- Deleo FR, Otto M, Kreiswirth BN and Chambers HF (2010): Community associated meticillin resistant Staphylococcus aureus. Lancet; 375: 9725-1557.

[2]- Esposito S, Noviello $S$ and Leone $S$ (2016). Epidemiology and microbiology of skin and soft tissue infections: Curr Opin Infect Dis; 29:109-15.

[3]- Buhl M, Peter S and Willmann M (2015): Prevalence and risk factors associated with colonization and infection of extensively drugresistant Pseudomonas aeruginosa. Anti-Infect. Ther ; 13:1159-1170.

[4]- Jääskeläinen IH, Hagberg L, Forsblom E and Järvinen A (2017): Microbiological Etiology and Treatment of Complicated Skin and Skin Structure Infections in Diabetic and Nondiabetic Patients in a Population-Based Study. Open Forum Infect Dis; 4 : 0-44.

[5]- Collee JG, Marr W.Specimen collection,: Collee JG, Fraser AG, Marmion BP, Simmons A, editors.Mackie and McCartney's (2012): culture containers \& media.In Practical Medical Microbiology; 95-111.

[6]- CLSI (2012). Performance Standards for Antimicrobial Disc Susceptibility Tests; Approved standard $11^{\text {th }}$ edition. CLSI document M02A11.Wayne,PA:Clinical and Laboratory Standards Institute.

[7]- Jarlier V, Nicolas M, Fournier G and Philippon A (1988). Extended spectrum $\beta$-lactamases conferring transferable resistance to newer $\beta$-lactam agents in 
Enterobacteriaceae: Hospital prevalence and susceptibility patterns. Rev Infect Dis;10:867-78.

[8]- Malhotra SK, Malhotrs S, Dhaliwal GS and Thakur A (2012): Bacteriological Study of Pyodermas in a tertiary Care Dermatological Center. Indian J Dermatol ; 57 : 358-61

[9]- Mohanty S, Kapil A, Dhawan B and Das BK (2004): Bacterilogical and antimicrobial susceptibility profile of soft tissue infections from northern India .Indian J Med Sci;58:10-15.

[10]- Afroz, Z. , Metri C and Jyothi P. (2015). Bacteriological profile and antimicrobial susceptibility pattern of skin and soft tissue infections among gram negative bacilli in a tertiary care hospital of south India. Journal of Pharmaceutical Sciences and Research; 7: 397-400.

[11]- Sah $P$, Khanal $R$ and Upadhaya $S$ (2013): Skin and soft tissue infections: Bacteriological profile and antibiotic resistance pattern of the isolates. $J$ Universal College of Medical Science ;18-21.
[12]- Soumya K and Jaya S (2014): Prevalence and antimicrobial susceptibility patterns of bacteria isolated from skin and wound infections. J Microbiol. Biotech. Res; 4 : 39-45.

[13]- Matthew S. Dryden (2010): Complicated skin and soft tissue infection. J Antimicrob Chemother; 65 : $35-44$.

[14]- Seni J, Najjuka CF, Kateete DP, Makobore P, Joloba ML, Kajumbula H, et al (2013): Antimicrobial resistance in hospitalized surgical patients: a silently emerging public health concern in Uganda. BMC Res Notes; 27(6):298. 